\title{
Direct and Indirect Associations between Family Residential Mobility, Parent Functioning, and Adolescent Behavioral Health
}

\author{
Xi Du $\mathbb{1}^{1} \cdot$ Youn Kyoung Kim $\mathbb{D}^{1}$
}

Accepted: 27 September 2021 / Published online: 14 October 2021

(C) The Author(s), under exclusive licence to Springer Science+Business Media, LLC, part of Springer Nature 2021

\begin{abstract}
Residential mobility and caregiver social support are two key factors influencing adolescents' and their caregivers' health status. However, few studies have examined whether these factors vary across developmental periods. The present study therefore adopted a life course perspective to investigate the longitudinal effects of residential mobility and caregiver social support on a range of individual health outcomes (i.e., caregiver depression, adolescent internalizing problems, and adolescent externalizing problems) among families exposed to disadvantaged social and economic conditions. Data were obtained from the Longitudinal Studies in Child Abuse and Neglect, and 425 children and their caregivers who completed the age 12,14, 16, and 18 interviews were included in this study. Structural equation modeling was conducted to test the measurement and structural models. The results showed that greater residential mobility was significantly associated with higher levels of caregiver depression, which in turn led to more adolescent internalizing and externalizing problems. Alternatively, higher levels of caregiver social support mitigated the levels of caregiver depression, which in turn resulted in fewer adolescent internalizing and externalizing problems. Highly mobile children and their caregivers were found to be vulnerable to several negative health outcomes and in high need of mental and behavioral health support and services. These findings inform important policy and practice implications on social support for mobile caregivers to address their children's behavioral problems.
\end{abstract}

Keywords Residential mobility $\cdot$ Caregiver social support $\cdot$ Caregiver depression • Adolescent internalizing problems $\cdot$ Adolescent externalizing problems

\section{Highlights}

- This study examined the associations between residential mobility, caregiver social support, caregiver depression, and adolescent behavioral problems among disadvantaged families.

- Greater childhood residential mobility is associated with increased adolescents' behavioral health problems.

- Caregiver social support is a significant protective factor for decreasing adolescents' behavioral health problems.

- Caregiver depression mediates the associations between residential mobility and caregiver social support, respectively, with adolescents' health outcomes.

- The findings inform important policy and practice implications in addressing residential instability and behavioral health problems.

\section{$\mathrm{Xi} \mathrm{Du}$}

xdu9@1su.edu

1 School of Social Work, Louisiana State University, Baton Rouge, LA 70803, USA

\section{Introduction}

Housing instability, including moving frequently and lack of affordable housing, has become one of the biggest threats posed by the COVID-19 pandemic (National League of Cities, 2020). Although temporarily expanded unemployment insurance, federal stimulus payments, and eviction moratoria keeping most Americans in their homes, with most of these supports now expired and political gridlock 
creating uncertainty around whether and how much they may be extended, concerns about housing instability are now taking on even greater urgency. Even before the pandemic, families and children experiencing homelessness constituted a majority among the homeless population (a January 2019 figure estimates 171,670 homeless families with at least one adult and one child under the age of 18), representing one-third of the overall homeless population in the U.S. (Department of Housing and Urban Development, 2020). Highly mobile families in poverty, notably, homeless families with children can exert substantial efforts on parents and children, leaving them vulnerable to numerous adverse health and developmental outcomes (Annor \& Oudshoorn, 2019; National Alliance to End Homelessness, 2020; Rog et al., 2015).

Children who grow up in disruptive environments, such as frequent residential moves, have heightened vulnerability to psychological and behavioral difficulties (Fowler et al., 2015). Such issues in adolescence may influence functioning in social situations (Miller-Graff et al., 2017), academic achievement (Voight et al., 2020), and overall well-being throughout an individual's life (Fowler et al., 2015). The same life stressors that disturb the healthy development of children and adolescents may also negatively affect caregivers' mental health and parenting capacity (Sheidow et al., 2014), further deteriorating adolescent health development over the long term (Anderson et al., 2014). One way to help prevent adolescents from experiencing these difficulties is to provide resources to help improve caregiver and adolescent health outcomes, particularly for families exposed to disadvantaged social and economic conditions (Casale et al., 2015). Given these considerations, there is a need to identify contributing factors and mechanisms influencing the development of adolescents and their families, as this information could be used to further meet their needs and to inform the design of future preventive interventions.

Social determinants of health are a theoretical perspective for understanding various factors influencing individual health development and can provide research directions for disadvantaged adolescents and their families (Braveman \& Gottlieb, 2014). This theory suggests that "the conditions in which people are born, grow, live, work and age" shape individual health outcomes. Groups or individuals must make decisions related to their lifestyle and behavioral habits within the social context where such choices occur (World Health Organization, n.d.). It states that individuals' health outcomes and qualities of life are determined by factors from five key areas: economic stability (e.g., housing instability), education (e.g., early childhood education and development), social and community contexts (e.g., social cohesion), health and health care (e.g., access to primary care), and neighborhood and built environment (e.g., environmental conditions; World Health Organization, n.d.). Informed by these determinant factors, the present study examined the linkages between two main determinants of health (residential mobility as a risk factor and caregiver social support as a protective factor) and a range of individual health outcomes (caregiver depression, adolescent internalizing problems, and adolescent externalizing problems).

\section{Residential Mobility, Caregiver Depression, and Children's Behavioral Health}

Research into health disparities has consistently found an adverse association between residential mobility in early life and health outcomes throughout an individual's life (Jelleyman \& Spencer, 2008; Morris et al., 2018). Residential mobility refers to a household or individual moving from their primary residence to another residence (Theodos et al., 2018). Although there is no universally recognized standard definition for high residential mobility, it has generally been demonstrated that the probability of behavioral problems increase with more residential relocations, especially when many of these moves occur during childhood (Morris et al., 2018). High family mobility in poverty is a potential sign of family homelessness. Most researchers agree that the pathway leading highly mobile families to homelessness is not an isolated process but is shaped in multiple contexts (Annor \& Oudshoorn, 2019; Howland et al., 2017; Teo \& Chiu, 2016). In early studies, homelessness was often attributed to personal deficits, such as older age, gender, race minority, low education level, long-term substance abuse, serious physical or mental health issues, and/or incarceration (Goering et al., 2002; Winetrobe et al., 2017). Some research also identified family dysfunction characterized by little/no social support, domestic violence, and/ or maltreatment as major causes of homelessness (Fisher et al., 2014). Despite the effects of personal or family risk factors on the pathway to homelessness, there has been a growing recognition that poor economic conditions and inadequate social services are leading social determinants in shaping family homelessness (Abdul Rahman et al., 2015; Gould \& Williams, 2010). The lack of supportive policies and resources on housing and other determinants of health (e.g., education, employment, health care) may exacerbate the adverse situations among disadvantaged families (Gould \& Williams, 2010).

Highly mobile individuals are vulnerable to numerous internalizing and externalizing behavior problems (Anderson et al., 2014) and in higher need of mental health screening and services (Susukida et al., 2016). Compared to their more stable peers, adolescents who moved more often during childhood showed a greater prevalence for drug 
abuse (Stabler et al., 2015), higher rates of attempted suicide (Tseliou et al., 2016), major depressive episodes (Susukida et al., 2016), violent offenses and premature death (Webb et al., 2016), as well as lower academic performance and lower rates of school attendance (Voight et al., 2020). Jelleyman and Spencer (2008) argued that greater residential mobility rates influenced health outcomes due to discrepancies between needs and resources. As a result of frequent environmental changes in early life, an individual's education, employment, and family relationships are likely to shift often, which might result in new life event stressors affecting an individual's mental health status in negative ways (Tunstall et al., 2012). Previous studies demonstrated that residential mobility affected women more than men because women generally suffered more stress from housework, childcare, and career sacrifices due to moving, which predicted depression (Magdol, 2002). Mobile children could be more vulnerable than mobile adults due to living in unstable circumstances because they have less power over mobility decisions and suffer more complete losses of physical, social networks (Morris et al., 2018). Therefore, frequent residential moves can be regarded as a familial risk marker for adolescents and their caregivers.

Some research suggests that family context, particularly the well-being of highly mobile parents, could explain the associations between residential mobility and children's health outcomes (Adam \& Chase-Lansdale, 2002; Anderson et al., 2014). Indeed, the environment of families that exhibit with high residential mobility is likely to be characterized by high degrees of family stress and dysfunction (Bradshaw et al., 2010), which is significantly associated with caregiver depression (Davis et al., 2008; Dempsey et al., 2016). Caregiver depression can affect different aspects of parenting, such as interactive behavior and discipline style. Additionally, adolescents who live with depressed caregivers are at an elevated risk of developing considerable internalizing and externalizing problems (Benito-Gomez et al., 2019; Du \& Kim, 2020; Foster et al., 2008). However, if caregivers did not report experiencing stress from a move, such associations were attenuated (Anderson et al., 2014).

\section{Caregiver Social Support, Caregiver Depression, and Children's Behavioral Health}

Caregiver social support is a significant protective factor for promoting caregiver mental health and adolescent psychosocial outcomes after adverse experiences (Casale et al., 2015; Miller-Graff et al., 2017). Evidence suggests that access to social support networks could alleviate some aspects of caregivers' depression by offsetting the challenges presented in their lives (Angley et al., 2015; GarcíaTorres et al., 2020; Kingston, 2013), particularly when they have experienced major disruptions, such as residential change or the death of a spouse (Weiss, 1974). Moran et al. (2019) found that the parents living in the disadvantaged circumstance of a refugee center in Ireland relied heavily on local services for emotional and financial support to cope with their living conditions. The availability of different types of social support might increase caregivers' selfesteem and self-efficacy, which could be regarded as a critical component for living a positive, healthy, and productive life (Chung-Yi et al., 2016).

Previous studies have also suggested that adolescents could benefit directly and indirectly from their caregivers' social support networks, especially at a younger age when they tend to spend a great deal of time with their caregivers (Miller-Graff et al., 2017). More caregiver social support has predicted higher social competence (Miller-Graff et al., 2017), better psychosocial well-being (Casale et al., 2015), and fewer behavior problems (Marshall et al., 2001) among adolescents. One possible explanation for this mechanism is that a caregiver's social support network could act as a type of community parenting by providing adolescents with informal social control and support to deter their problematic outcomes (Maimon \& Browning, 2010; Prince et al., 2019). Furthermore, there is evidence for an indirect effect of caregiver social support on adolescent development through the impact of social support on caregiver mental health and parenting behaviors (Casale et al., 2015). Parents with high levels of social support are more likely to provide a warm and responsive home environment, which, in turn, leads to fewer behavioral problems in their children (Marshall et al., 2001).

To sum up, prior research demonstrates that residential mobility and caregiver social support are two key factors that influence the health status of adolescents and their caregivers. However, few studies have integrated residential mobility and caregiver social support into a unified framework to better understand their longitudinal impacts on adolescent health outcomes. Additionally, some studies highlight the significance of caregiver depression in processes linking residential mobility or caregiver social support to adolescent health outcomes (Anderson et al., 2014; Casale et al., 2015). Therefore, there is also a need to provide additional insights into the mediating effect of caregiver depression in a unified framework. A life course perspective allows for more detailed interpretations of those associations in the unified model (Morris et al., 2016). Specifically, the life course perspective emphasizes two relevant themes: developmental risk and protection as well as linked or interdependent lives (Elder, 1998). Negative early life experiences or transitions have future 
impacts that shape the trajectory of one's life (Hutchison, 2019). Furthermore, people are reciprocally linked on several levels and those relationships can support or control individuals' behavior (Hutchison, 2019). These themes of the life course perspective explain how experiencing major disruptions or adverse life events in early life can track into later life and influence health and development, as well as the mitigating influence of social support on adverse events (Clark, 2013).

\section{Present Study}

The present study adopted social determinants of health and life course perspectives to investigate the longitudinal effects of differing levels of residential mobility and caregiver social support on a range of individual health outcomes (caregiver depression, adolescent internalizing problems, and adolescent externalizing problems) among families exposed to disadvantaged social and economic conditions. Specifically, we hypothesized that: high residential mobility would have a direct and negative effect on caregiver depression as well as on adolescent internalizing and externalizing problems $\left(H_{l}\right)$; lower levels of caregiver social support would have a direct and negative effect on caregiver depression as well as on adolescent internalizing and externalizing problems $\left(H_{2}\right)$; caregiver depression would mediate the association between residential mobility and both adolescent internalizing problems and adolescent externalizing problems, respectively $\left(H_{3}\right)$; and caregiver depression would mediate the association between caregiver social support and both adolescent internalizing problems and adolescent externalizing problems, respectively $\left(H_{4}\right)$.

\section{Methods}

\section{Data Source and Sample}

The current study utilized secondary data from the Longitudinal Studies in Child Abuse and Neglect (LONGSCAN; Runyan et al., 2014), a survey investigating predictors and developmental consequences of the maltreatment of children and the risk of such maltreatment. As a multi-site research project, the LONGSCAN collected data from four primarily urban sites (Baltimore, Chicago, Seattle, and San Diego) and one statewide site that included urban, suburban, and rural communities (North Carolina). The sampling criteria varied across the five sites, ranging from the child participants in San Diego and Seattle who had a history with local Child Protective Services (CPS) to a portion of the child participants in
Baltimore, Chicago, and North Carolina with no known CPS records beyond low-income status. Each site shared common protocols for data collection, entry, and management (Runyan et al., 1998). The data collection process commenced in 1991 when the child participants were four years old. A total of 1,354 children and their families and teachers were followed in this survey. Evaluations of the children, their caregivers, and their teachers were conducted every two years; seven age-specific waves of data (at ages 4, 6, 8, 12, 14, 16, and 18) have been gathered so far. A more detailed description on the LONGSCAN survey can be found in studies by Runyan et al. (1998, 2014). Ethical approval for this study was waived by the Institutional Review Board of Louisiana State University because we were doing secondary data analysis of the publicly available dataset. Informed consent was not sought for the present study as the recorded information of participants cannot readily be identified.

The sample in this study included all children and their primary caregivers who completed the age $12,14,16$, and 18 interviews, which resulted in a final sample size of 425 dyads. Salient features of the samples are displayed in Table 1. In our sample, the participants from Baltimore, Seattle, North Carolina, San Diego, and Chicago site accounted for $22.8 \%, 21.9 \%, 19.8 \%, 18.4 \%$, and $17.2 \%$, respectively. Among the child participants, $51.2 \%$ were males, and $48.8 \%$ were females. African Americans represented a majority $(54.1 \%)$, followed by European Americans (27.3\%), multiracial people (18.0\%), and others $(0.6 \%)$. Regarding maltreatment status at recruitment, the majority $(70.5 \%)$ of our study sample had substantiated reports of maltreatment, and $20.2 \%$ had been reported as well as being believed to be at risk for maltreatment; the other (9.3\%) sample were children from low-income families, without involvement with CPS. Most of the primary caregivers were female (96.7\%). At the initial (age 4) interview, the average age of caregivers was 31.4 years old $(S D=9.9)$, with about two-thirds (67.9\%) of the caregivers reported their marital status as single/separated/divorced and $42.4 \%$ of them were either unemployed or did not work. With regard to the highest education level, $43.7 \%$ of the caregivers reported that they did not finish high school, 52.6\% had obtained a high school diploma or equivalency certificate, and $3.7 \%$ had obtained a bachelor's degree or a higher level of education. The average family size was 4.4 members $(S D=1.7)$, with $72.4 \%$ of the caregivers reporting a gross household income below $\$ 20,000$, which means more than two-thirds of our samples come from low-income families at the initial interview (1992-1996) considering that the poverty threshold for a four-person family was around $\$ 15,000$ (U.S. Census Bureau., n.d.) during that time. 
Table 1 Demographic Characteristics of the Sample at the Initial Interview $(N=425)$

\begin{tabular}{|c|c|c|c|c|}
\hline Variable & $\%(n)$ & Variable & $\%(n)$ & $M(S D)$ \\
\hline Site & & Age of Caregiver & & $\begin{array}{l}31.4(9 . \\
9)\end{array}$ \\
\hline Baltimore (Eastern) & $22.8(97)$ & Marital Status & & \\
\hline Seattle (Northwestern) & $21.9(93)$ & Married & $32.1(136)$ & \\
\hline North Carolina (Southern) & $19.8(84)$ & Single and never married & $45.3(193)$ & \\
\hline San Diego (Southwestern) & $18.4(78)$ & Separated/Divorced/Widowed & $22.6(96)$ & \\
\hline Chicago (Midwestern) & $17.2(73)$ & $\begin{array}{l}\text { Caregiver Highest } \\
\text { Education Level }\end{array}$ & & \\
\hline Child Gender & & Below high school & $43.7(186)$ & \\
\hline Male & $51.2(218)$ & High school or equivalency & $52.6(223)$ & \\
\hline Female & $48.8(207)$ & Bachelor's or above & $3.7(16)$ & \\
\hline Child Race & & Caregiver Employment & & \\
\hline African American & $54.1(230)$ & Employed or homemaker & $57.6(245)$ & \\
\hline European American & $27.3(116)$ & Unemployed or disabled to work & $19.4(82)$ & \\
\hline Multiracial people & $18.0(77)$ & $\begin{array}{l}\text { Didn't work due to retired or } \\
\text { student }\end{array}$ & $23.0(98)$ & \\
\hline Others & $0.6(2)$ & Household Income per Pear & & \\
\hline Maltreatment Status at Recruitment & & $<\$ 5,000$ & $13.7(58)$ & \\
\hline Reported & $70.5(300)$ & $\$ 5000-\$ 10,000$ & $28.6(122)$ & \\
\hline At risk & $20.2(86)$ & $\$ 10,000-\$ 15,000$ & $18.0(77)$ & \\
\hline None & $9.3(39)$ & $\$ 15,000-\$ 20,000$ & $12.1(51)$ & \\
\hline Caregiver Gender & & $>20,000$ & $27.6(117)$ & \\
\hline Female & $96.7(411)$ & Household Size & & $4.4(1.7)$ \\
\hline Male & $3.3(14)$ & & & \\
\hline
\end{tabular}

\section{Measures}

\section{Adolescent internalizing and externalizing problems [Endogenous variables]}

Adolescent internalizing and externalizing problems were measured separately using subscales derived from the caregiver-reported Child Behavior Checklist/4-18 (CBCL/ 4-18; Achenbach, 1991) at the age 16 interview. The CBCL/4-18 is a widely used questionnaire employed to examine child and youth behavior/emotional problems and competencies, and it has shown good performance on content, construct, and criterion validity (Achenbach \& Ruffle, 2000). Measures of internalizing problems comprised three subscales: anxiety/depression, somatic complaints, and social withdrawal, while measures on externalizing problems consisted of two subdomains: aggressive behavior and delinquent behavior. Primary caregivers reported the frequencies at which their children exhibited various behavioral/emotional problems (e.g., "sudden changes in mood or feelings," "impulsive or acts without thinking," and "physically attacks people") within the prior six months. The responses were rated on a three- point Likert scale ranging from 0 (not true) to 2 (very true or often true). Age-standardized $T$-scores were used in the statistical analyses, with a possible total $T$-score range of 30-100. Higher scores suggested more adolescent internalizing or externalizing problems. The Cronbach's alphas for the sample on adolescent internalizing and externalizing problems were 0.90 and 0.91 , respectively.

\section{Residential mobility [Exogenous variable]}

Residential mobility was measured using questions created by LONGSCAN investigators (Runyan et al., 2014) for the age 18 interview. Adolescents were asked questions such as "How many different homes or apartments did you live in before you started the first grade?" and "How many different homes or apartments did you live in from first grade through 11 years of age?" Possible responses to each question ranged from 1 (1) to 5 (5 or more). To capture the number of residence changes experienced from birth through age 11, the responses for the two questions were added to create an observed factor representing residential mobility through age 11. The total score could range from 2 to 10 , for which greater values indicated greater residential mobility through age 11 . 


\section{Caregiver social support [Exogenous variable]}

The Social Provisions Scale (SPS), developed by Cutrona and Russell (1987) and based on Weiss's (1974) social provisions theory, was used to examine the extent to which respondents' social relationships provided social support at the age-12 interview. The SPS captures the functions of social relationships in meeting individual's emotional and instrumental social support needs as well as the functions in influencing their perceived responsibility of offering support to others. It is useful for measuring the bidirectional nature of social support among people, especially among those who experienced major disruptions in their lives (Chiu et al., 2016). Previous studies have demonstrated that the SPS has strong reliability and validity in examining social resources among various adult samples, including first-time mothers, teachers, and college students (Cutrona et al., 1994). The 24-item SPS consists of six dimensions of social support: (1) attachment, (2) social integration, (3) reassurance of worth, (4) reliable alliance, (5) guidance, and (6) opportunity for nurturance. Sample items included statements such as "There are people I know that will help me if I really need it," "There are people who call on me to help them," and "I feel a strong emotional tie with at least one other person." Primary caregivers rated these statements on a four-point Likert scale ranging from 1 (strongly disagree) to 4 (strongly agree). Item scores were summed into a total score that could range from 24 to 96 , with higher scores indicating higher levels of social support. The Cronbach's alpha for the current sample was 0.74 .

\section{Caregiver depression [Mediating variable]}

The measures of caregiver depression at the age 14interview came from the Center for Epidemiologic Studies Depression Scale (CES-D; Radloff, 1977). Evidence for construct validity and concurrent validity by clinical and self-report criteria of this scale for the general population is well documented (Radloff, 1977). The original CES-D includes 20 items assessing four subdomains of major depression symptoms: depressed affect, low positive affect, somatic complaints, and interpersonal problems. Primary maternal caregivers were asked to report the frequencies at which they had experienced depressive symptoms over the prior week on a four-point Likert scale ranging from 0 (rarely or none of the time/less than one day) to 3 (most or all of the time/5-7 days). Sample items included "I felt lonely", "I did not feel like eating", and "I felt people were unfriendly". The possible total score range was $0-60$, with higher scores indicating higher levels of depressive symptoms. The Cronbach's alpha for the current sample was 0.89 .
Adolescents' gender and family functioning [Control variables]

Adolescents' gender and their family functioning at the age12 interview were selected as control variables because previous research has suggested that these variables tend to affect adolescent behavior problems. For example, by exploring changes in self-rated emotional and behavioral problems in adolescents, Konowałek and Wolanczyk (2018) found that male adolescents were more likely to increase their externalizing behaviors; whereas, female adolescents were at greater risk of internalizing their behavioral problems. Regarding family functioning, there is evidence that high levels of family functioning were significantly associated with lower levels of caregiver depression which, in turn, was associated with lower levels of adolescent internalizing and externalizing problems ( $\mathrm{Du} \&$ Kim, 2020).

In our study, adolescents' gender was coded as $1=$ male and $0=$ female. Their family functioning was measured using the 36-item Self-Report Family Inventory (SFI; Beavers et al., 1990). Adolescents' primary maternal caregivers were asked to rate each statement (e.g., "Grownups in the household compete and fight with each other," "We argue a lot and never solve problems") on a five-point Likert scale ranging from 1 (fits our household very well) to 5 (does not fit our household at all). The total scores can range from 44 to 220 , with higher scores indicating better family functioning. The Cronbach's $\alpha$ for the current sample was 0.85 .

\section{Data Analysis}

All the analyses in this study were conducted using the $\mathrm{R}$ computer program (R Core Team, 2019). Preliminary analyses including descriptive statistics and examination of bivariate correlations among variables, were performed first.

The primary analyses that involved testing the measurement model and the structural model were conducted with the "lavaan" package (Rosseel, 2012) using R. We use the full information maximum likelihood (FIML) method to address missing data $(<17 \%)$. In non-normality among variables, the MLM estimator denoting maximum likelihood estimation with robust standard errors, and the Satorra-Bentler scaled test statistic via $\mathrm{R}$ were utilized to estimate the model parameters (Rosseel, 2012). Values of TLI and CFI exceeding 0.95 indicated an adequate model fit to the data (Hu \& Bentler, 1999). An RMSEA value of less than 0.05 indicated a close model fit, and values between 0.05 and 0.08 suggested an acceptable approximation (Browne \& Cudeck, 1992).

We started with estimating a proposed measurement model. The proposed measurement model included four 
latent variables (i.e., caregiver social support, caregiver depression, adolescent internalizing problems, and adolescent externalizing problems). The relevant measures of these variables acted as indicators in the model. Once a measurement model with an adequate fit was confirmed, a proposed structural model was tested to assess the hypothesized relationships among the variables. In the structural model, residential mobility and caregiver social support were denoted as exogenous variables because other variables in the model could not predict them; adolescent internalizing and externalizing behavior problems were endogenous variables because they were dependent variables in this study and could be explained by one or more other variables; caregiver depression served as a mediating variable that would explain the process through which two variables were related. Specifically, the model estimated the direct paths among residential mobility through age 11, caregiver social support at age 12, caregiver depression at age 14 , and adolescent internalizing and externalizing problems at age 16, as well as indirect paths in which caregiver depression at age 14 played a mediation role.

\section{Results}

\section{Correlations}

Table 2 describes the correlations among primary variables (adolescent internalizing problems, adolescent externalizing problems, residential mobility, caregiver social support, caregiver depression) and control variables (family functioning and gender) in our study. Regarding primary variables, adolescent internalizing problems had a significant and positive correlation with their externalizing problems $(r=0.72, p<0.001)$. Likewise, adolescent internalizing problems had significant and positive correlations with residential mobility $(r=0.11, p<0.05)$ and caregiver depression $(r=0.21, p<0.001)$. On the other hand, adolescent externalizing problems were only positively correlated with caregiver depression $(r=0.18, p<0.001)$. They were not significantly correlated with residential mobility or caregiver support. Furthermore, caregiver depression was positively correlated with residential mobility $(r=0.15, p<0.01)$ and negatively correlated with caregiver social support $(r=-0.40, p<0.001)$. However, residential mobility was not significantly correlated with caregiver social support. In terms of control variables, family functioning significantly correlated with other variables except gender, and gender was not significantly correlated with any variables.

\section{Measurement Model}

The initial measurement model of the current study demonstrated an acceptable fit to the data $\left(\chi^{2}(84)=\right.$ 159.111, $p<0.001$; TLI $=0.947$; $\mathrm{CFI}=0.951 ;$ RMSEA $=$ $0.054,90 \%$ CI $[0.049,0.67])$. All indicators in the initial model had a factor loading that was larger than 0.50 and were significant at the $p<0.001$ level, except the positive effect indicator for the latent variable called caregiver depression. Given this indicator was not well mapped on its latent variable in this study, it was excluded from the final model. This operation is also supported by previous studies demonstrating the advantages of deleting the four items related to the positive effect of the original CES-D (Edwards et al., 2010; Stansbury et al., 2006), the instrument that was used to measure caregiver depression in this study. Furthermore, the modification indices of the initial measurement model suggested that the model fit could be improved by allowing (1) the residuals of depressed affect and somatic complaints of caregiver depression and (2) the residuals of somatic complaints of caregiver depression and delinquent behavior for the covariance of adolescent externalizing problems. With the reduced number of indicators and the incorporation of the error covariances, the results of the final measurement model showed an excellent
Table 2 Intercorrelations and descriptive statistics among study variables and control variables $(N=425)$

\begin{tabular}{lccccccc}
\hline & 1 & 2 & 3 & 4 & 5 & 6 & 7 \\
\hline 1. Adolescent internalizing problems_16 & - & & & & & & \\
2. Adolescent externalizing problems_16 & $0.72^{* * *}$ & - & & & & & \\
3. Residential mobility $\leq 11$ & $0.11^{*}$ & 0.09 & - & & & & \\
4. Caregiver social support_12 & -0.00 & -0.01 & -0.07 & - & & & \\
5. Caregiver depression_14 & $0.21^{* * *}$ & $0.18^{* * *}$ & $0.15^{* *}$ & $-0.40^{* * *}$ & - & & \\
6. Family functioning_12 & $-0.16^{* *}$ & $-0.17^{* * *}$ & $-0.12^{*}$ & $0.42^{* * *}$ & $-0.39^{* * *}$ & - & - \\
7. Gender & 0.04 & 0.09 & -0.08 & -0.07 & -0.01 & 0.03 & - \\
Range & $31-84$ & $32-91$ & $2-10$ & $34-96$ & $0-51$ & $74-174-$ \\
$M$ & 48.88 & 52.89 & 4.53 & 79.11 & 11.03 & $144.85-$ \\
$S D$ & 11.54 & 11.57 & 2.00 & 10.35 & 9.96 & 16.75 & - \\
$* p<0.05, * * p<0.01, * * * p<0.001$. & & & & & &
\end{tabular}


Fig. 1 Measurement model with standardized coefficients. $\chi^{2}$ $(67)=103.503, p<0.05$, TLI $=$ $0.981, \mathrm{CFI}=0.986$, RMSEA $=$ $0.039, * p<0.05, * * p<0.01$, $* * * p<0.001$

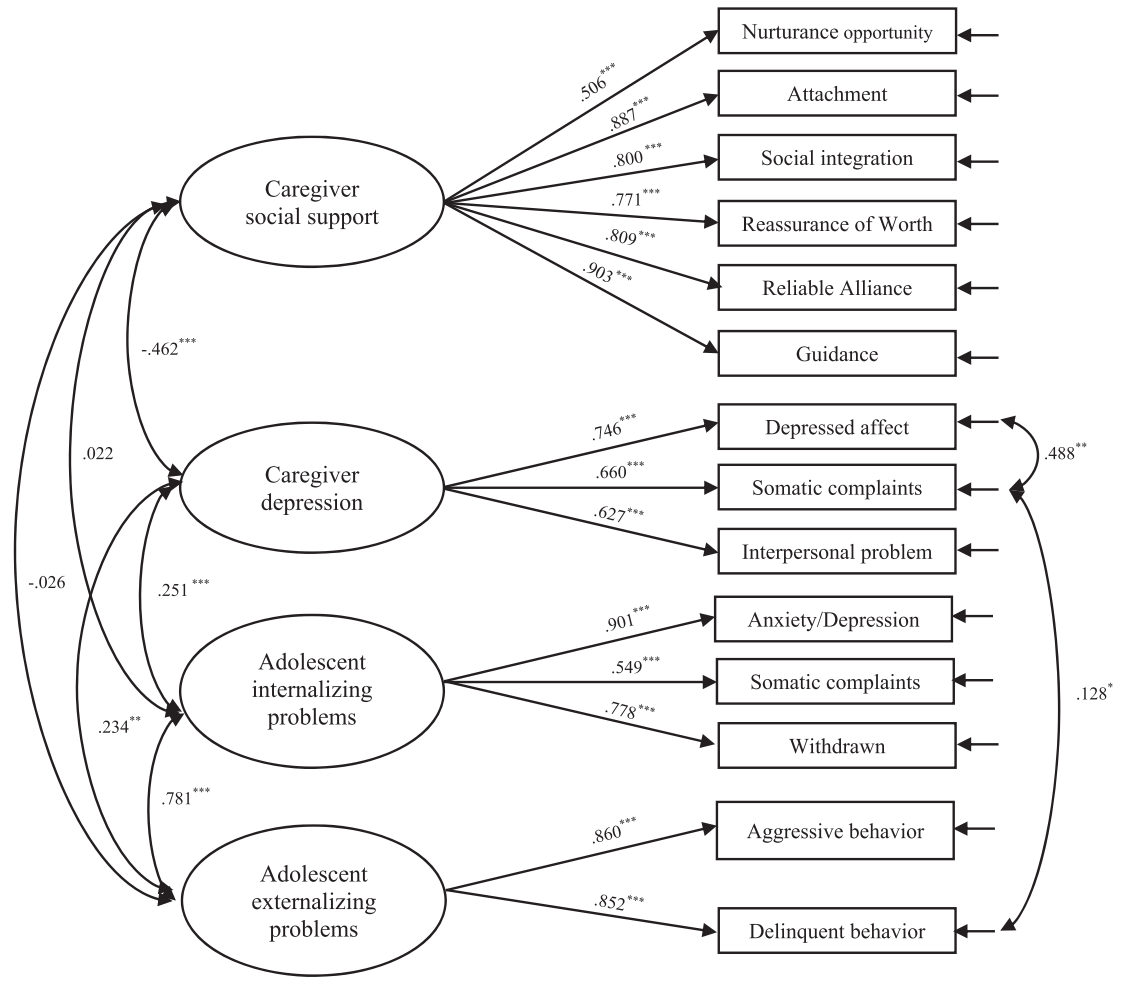

fit for the observed data $\left(\chi^{2}(67)=103.503, p<0.05\right.$; TLI $=$ $0.981 ; \mathrm{CFI}=0.986 ; \quad \mathrm{RMSEA}=0.039,90 \%$ CI $[0.026$, 0.049]). The final measurement model is presented in Fig. 1.

\section{Structural Model}

The results of the structural model are shown in Fig. 2 and Table 3, explaining both direct and indirect effects of the exogenous variables (residential mobility during childhood and caregiver social support) on the endogenous variables (internalizing and externalizing problems) through the mediator (caregiver depression). The fit indices indicated that the proposed model fit the data well $\left(\chi^{2}(79)=131.194\right.$, $p<0.001 ; \quad \mathrm{TLI}=0.975 ; \quad \mathrm{CFI}=0.981 ; \quad \mathrm{RMSEA}=0.042$, $90 \%$ CI $[0.029,0.051])$.

\section{Direct effects}

As shown in Fig. 2, a total of eight direct paths were estimated. Six of these direct paths were statistically significant: $\left(a_{1}\right)$ the direct path from residential mobility to caregiver depression was positively significant $(\beta=0.143, p<0.01)$; $\left(a_{2}\right)$ the direct path from caregiver social support to caregiver depression was negatively significant $(\beta=-0.359$, $p<0.01) ;\left(b_{1}\right)$ the direct path from caregiver depression to adolescent mental problems was positively significant $(\beta=$ $0.280, p<0.001)$; $\left(b_{2}\right)$ the direct path from caregiver depression to adolescent behavioral problems was positively significant $(\beta=0.232, p<0.01)$; $\left(c_{2}\right)$ the direct path from residential mobility to adolescent behavioral problems was positively significant $(\beta=0.098, p<0.05)$; $\left(c_{3}\right)$ the direct path caregiver social support to adolescent mental problems was negatively significant $(\beta=-0.151, p<0.01)$. These results showed that residential mobility had a direct effect on adolescent externalizing problems but did not directly relate to adolescent internalizing problems; caregiver social support had a direct effect on adolescent internalizing problems but did not directly relate to adolescent externalizing problems; but, the two exogenous variables (residential mobility and caregiver social support) were both directly associated with the mediator (caregiver depression) and the mediator was directly associated in the SEM model with the two endogenous variables, adolescent internalizing and externalizing problems, respectively. Besides, high residential mobility was associated with higher levels of caregiver depression, and lower levels of caregiver social support were also associated with higher levels of caregiver depression. Then higher levels of 
Fig. 2 Structural model with standardized path coefficients. $\chi^{2}(79)=131.194, p<0.001$, $\mathrm{TLI}=0.975, \mathrm{CFI}=0.981$, RMSEA $=0.042,{ }^{*} p<0.05$, ${ }^{* * *} p<0.01,{ }^{* * * *} p<0.001$

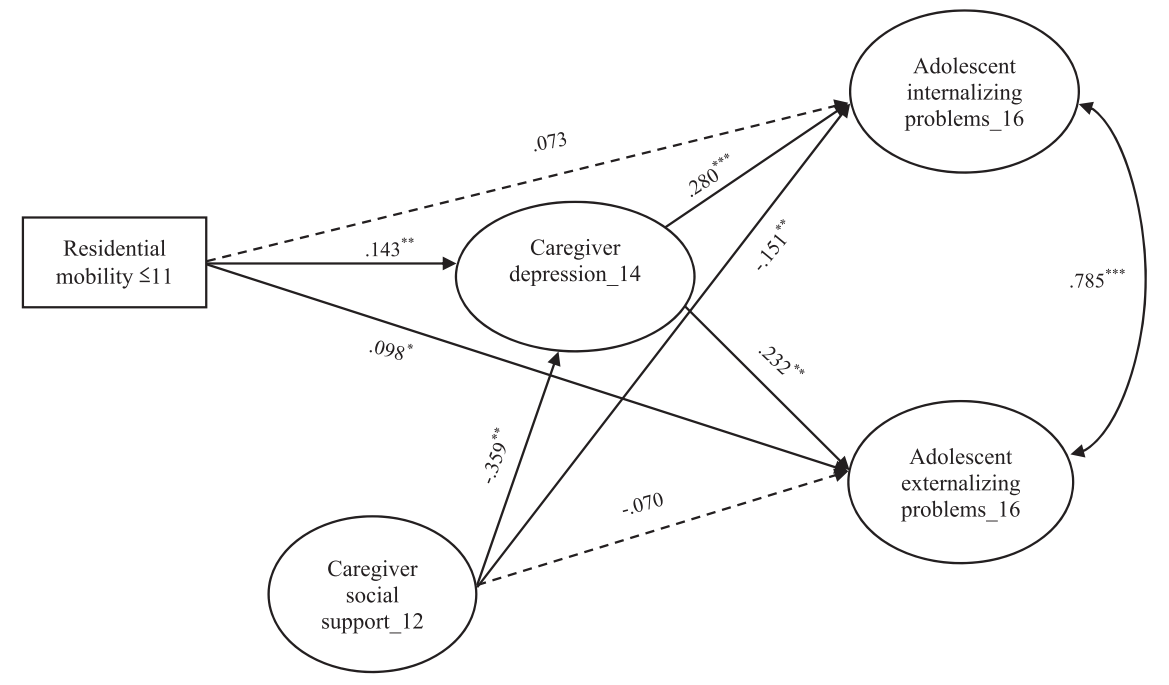

Table 3 Results of the mediated path analysis (standardized estimates)

\begin{tabular}{lrrrr}
\hline & $\beta$ & SE & \multicolumn{1}{l}{$t$} \\
\hline Direct Effect & & & & \\
$\mathrm{RM} \leq 11 \rightarrow$ AIP_16 & 0.073 & 0.057 & 1.625 & 0.104 \\
$\mathrm{RM} \leq 11 \rightarrow$ CD_14 & 0.143 & 0.030 & 2.701 & $\mathbf{0 . 0 0 7}$ \\
$\mathrm{RM} \leq 11 \rightarrow$ AEP_16 & 0.098 & 0.069 & 1.983 & $\mathbf{0 . 0 4 7}$ \\
$\mathrm{CSS}$ 12 $\rightarrow$ AIP_16 & -0.151 & 0.092 & -2.503 & $\mathbf{0 . 0 1 2}$ \\
CSS_12 $\rightarrow$ CD_14 & -0.359 & 0.025 & -3.368 & $\mathbf{0 . 0 0 1}$ \\
CSS_12 $\rightarrow$ AEP_16 & -0.070 & 0.086 & -1.250 & 0.211 \\
CD_14 $\rightarrow$ AIP_16 & 0.280 & 0.053 & 3.541 & $<\mathbf{0 . 0 0 1}$ \\
CD_14 $\rightarrow$ AEP_16 & 0.232 & 0.067 & 3.058 & $\mathbf{0 . 0 0 2}$ \\
Indirect Effect & & & & \\
RM $\leq 11 \rightarrow$ CD_14 $\rightarrow$ AIP_16 & 0.038 & 0.039 & 2.601 & $\mathbf{0 . 0 0 9}$ \\
RM $\leq 11 \rightarrow$ CD_14 $\rightarrow$ AEP_16 & 0.030 & 0.034 & 2.251 & $\mathbf{0 . 0 2 4}$ \\
CSS_12 $\rightarrow$ CD_14 $\rightarrow$ AIP_16 & -0.099 & 0.041 & -3.202 & $\mathbf{0 . 0 0 1}$ \\
CSS_12 $\rightarrow$ CD_14 $\rightarrow$ AEP_16 & -0.078 & 0.042 & -2.712 & $\mathbf{0 . 0 0 7}$ \\
\hline
\end{tabular}

$R M \leq 11$ Residential Mobility through age 11, AIP_16 Adolescent Internalizing Problems at age 16, AEP_16 Adolescent Externalizing Problems at age 16,CSS_12 Caregiver Social Support at age 12, CD_14 Caregiver Depression at age 14.

Bold values indicates statistically significant $P$ values.

caregiver depression were positively associated with adolescent internalizing and externalizing problems.

\section{Indirect effects}

As described in Table 3, there were four significant mediating effects: caregiver depression mediated (1) the relationship between residential mobility and internalizing problems $(\beta=0.038, p<0.01)$; (2) the relationship between residential mobility and externalizing problems $(\beta=0.030$, $p<0.05$ ); (3) the relationship between caregiver social support and internalizing problems $(\beta=-0.099, p<0.01)$; and (4) the relationship between residential mobility and externalizing problems $(\beta=-0.078, p<0.01)$. The results showed that greater residential mobility was significantly associated with higher levels of caregiver depression, which led to more adolescent internalizing and externalizing problems. However, higher levels of caregiver social support could mitigate the levels of caregiver depression, which in turn resulted in fewer adolescent internalizing and externalizing problems later. Moreover, the indirect effect sizes of caregiver social support on adolescent internalizing ( $\beta=$ $-0.099)$ and externalizing $(\beta=-0.078)$ problems were greater than that of residential mobility on adolescent internalizing $(\beta=0.038)$ and externalizing $(\beta=0.030)$ problems, respectively.

\section{Discussion}

The primary focus of the current study was to investigate the longitudinal effects of two main determinants of health (residential mobility and caregiver social support) on a range of individual health outcomes (caregiver depression, adolescent internalizing problems, and adolescent externalizing problems) among families exposed to disadvantaged social and economic conditions, based on the theoretical framework of social determinants of health and a life course perspective. Overall, the results partially supported our 
hypotheses. First, slightly different from $H_{1}$ in which we supposed high residential mobility would have a direct and negative effect on caregiver depression as well as on both adolescent internalizing and externalizing problems, the findings showed that high residential mobility had direct and negative effects on caregiver depression and adolescent externalizing problems, but it was not directly associated with adolescent internalizing problems. Specifically, the direct association between residential mobility and caregiver depression is consistent with prior studies that frequent moving had adverse effects on mental health outcomes among caregivers, including depression, stress, and anxiety (Anderson et al., 2014; Magdol, 2002; Morris et al., 2018; Roze et al., 2018). According to Magdol (2002), residential mobility affects women more than men because women generally suffer more stress from housework, childcare, and career sacrifices due to moving, which predicts depression. Since $96.7 \%$ of caregivers in our study were female and lived in disadvantaged families, it is not surprising to see that caregivers with higher residential mobility experienced higher levels of depressive symptoms.

Furthermore, adolescents who lived in a family with frequent residential moves in early life showed more externalizing problems during adolescence. This finding supports prior research displaying a significant link between childhood residential mobility and their outer-directed behavioral problems during adolescence, such as physical aggression, verbal bullying, drug use, and delinquent behaviors (Jelleyman \& Spencer, 2008; Stabler et al., 2015; Voight et al., 2020; Webb et al., 2016). However, childhood residential mobility was not directly associated with adolescent internalizing problems in our sample; it was only indirectly associated with adolescent internalizing problems through caregiver depression. This finding contradicts with previous studies that have found a significant direct relationship between childhood residential mobility and innerdirected distress in adolescents (Susukida et al., 2016; Tseliou et al., 2016). Nevertheless, our results conform to Mok and colleagues' work (2016) in which the adverse influence of childhood residential mobility was particularly strong for adolescent behavioral problems (e.g., antisocial, substance misuse, and cannabis misuse). In contrast, the risk of mental health problems (e.g., anxiety disorders) was found to be little to none.

In $\mathrm{H}_{2}$, we hypothesized that lower levels of caregiver social support would directly and negatively relate to caregiver depression and both internalizing and externalizing problems. While the findings showed that lower levels of caregiver social support were directly associated with caregiver depression and adolescent internalizing problems, caregiver social support was not directly linked to adolescent externalizing problems, which aligns with previous research (Angley et al., 2015; García-Torres et al., 2020;
Kingston, 2013). Previous research highlighted that the alleviation effect of social support on depression is particularly strong for individuals who have experienced major disruptions (Weiss, 1974), which provides further support for our findings because our sample came from families exposed to disadvantaged social and economic conditions. Although there is a consistent finding with previous studies (Brown, 2015; Casale et al., 2015) demonstrating that caregiver social support is a protective factor for adolescent mental health, our finding of an insignificant connection between caregiver social support and adolescent externalizing behavioral health is discrepant from previous research, where more caregiver social support predicted fewer adolescent outer-directed behavioral problems (Marshall et al., 2001; Miller-Graff et al., 2017). This may be because the operationalization of caregiver social support in this study is more related to the emotional provision of social support for caregivers, including attachment (refers to feelings of intimacy, peace, and security), social integration (denotes a sense of belonging to a group), and reassurance of worth (refers to having others validate one's competence and value). Weiss' social provisions theory (1974) also emphasizes the effects of social resources on individuals' emotional and somatic symptoms (e.g., loneliness, disturbed sleep, and generalized dissatisfaction) rather than behavioral problems.

This study found that all of the mediating (indirect) effects of the hypothesized model were significant, supporting $\mathrm{H}_{3}$ and $\mathrm{H}_{4}$, which proposed caregiver depression would mediate the direct effects of residential mobility and caregiver social support, respectively, on both adolescent internalizing and externalizing behavior problems. The findings contribute to the literature by expanding the previous research to include the mediating effect of caregiver depression on the relationship between residential mobility and adolescent behavioral health outcomes. Previous research was focused only on associations among unstable family context (i.e., mobile parents' compromised wellbeing), high residential mobility, and children's health outcomes in general (Adam \& Chase-Lansdale, 2002; Anderson et al., 2014). We found that more frequent residential change was associated with caregiver depression, which led to more adolescent internalizing problems and externalizing problems, respectively $\left(H_{3}\right)$. Furthermore, the results revealed that caregiver depression significantly mediated the association between caregiver social support and internalizing problems, as well as the association between caregiver social support and externalizing problems $\left(H_{4}\right)$. These findings are consistent with prior studies. For example, Casale et al. (2015) investigated the effects of caregiver social support on adolescent psychological outcomes among 2477 South African adolescents in two South African AIDS-affected communities and found that the 
direct effects of caregiver social networks on adolescent psychosocial well-being were mediated by caregiver mental health. Our study highlights how social support reduces caregiver depression symptoms which in turn is likely to benefit children's health behaviors. Moreover, the indirect effect sizes of caregiver social support on adolescent mental and behavioural problems were greater than those of residential mobility on adolescent internalizing and externalizing problems. This finding provides an important implication that strengthening caregivers' social support may prevent the deterioration of their mental health and children's health outcomes in adolescence associated with the adverse influence of childhood residential mobility.

\section{Limitations}

The findings described in this study should be taken with consideration of the context of their limitations. First, this study used purposive sampling, which means the sample was not representative. The participants came from fragile families and were maltreated, neglected, or in danger of maltreatment and/or neglect. Thus, this sample might show higher prevalence rates of residential mobility, lower social support, and poorer health outcomes. Second, the measures of all variables except residential mobility relied upon caregivers' self-reporting. Thus, response bias cannot be avoided. Third, our structural model was limited to include only one mediator in the family context: caregiver depression. In fact, the indirect pathways from residential mobility and caregiver social support in early life to adolescent health outcomes in later life may be intertwined with other contextual factors, such as school and peers, particularly considering that children interact not only with their family units but also systems outside their families as they mature (Catalano \& Hawkins, 1996). Future research should consider the additional mediating or moderating variables in the model. Fourth, choosing the variables at different times (i.e., residential mobility through age 11 , caregiver social support at age 12, caregiver depression at age 14, and adolescent behavioral problems at age 16) rather than at each age provides a better understanding of the timing and links among variables in a specific temporal order regarding child developmental periods (childhood/early adolescence to middle adolescence to late adolescence). However, this design cannot capture the changes that occur over time. This may potentially produce some bias, as it does not consider the contemporaneous and lagged correlations among the variables (MacKinnon et al., 2007). For future research, we suggest the use of longitudinal mediation models to handle various correlations and temporal order. Additionally, our structural model was limited to examine only one of the possible relationships between residential mobility, parent functioning, and adolescent behavioral health. In this study, we hypothesized high residential mobility had a direct and negative effect on caregiver depression, which further impacted adolescent internalizing and externalizing problems. However, it should be noted that mothers with greater depressive symptoms may have difficulty securing consistent income, and thus, they may experience more residential mobility as a result of their depressive symptoms. Therefore, future studies should examine alternative directions of effects so as to better understand their complicated associations with adolescent behavioral health.

In addition, we did not assess within-group differences regarding the nature of mobility. A move can be a positive response to housing-related problems and bring beneficial changes for households, such as getting employment opportunities, improving housing conditions, etc.; it can also be a negative choice when households gain little by moving and/or keep suffering from housing-related issues after moving due to eviction, loss of financial resources, divorce, or other involuntary reasons (Kang, 2019). Some researchers have suggested that a failure to differentiate health-selective migration from other passive migration may confuse the relationship between mobility and health (Morris et al., 2018). In contrast, only a few studies have explicitly examined the effects of different kinds of mobility on health. Blackman and colleagues (2003) suggested that individuals experienced a decrease in depression when their motives for relocation were voluntary and positive. Woodhead and colleagues (2015) found that residents who moved due to a lack of options for stable residence were more likely to have poorer mental health compared to those who experienced a desired move. This certainly warrants further exploration of the motives and decisions behind mobility to provide valuable empirical information in explaining the associations between residential mobility, caregiver social support, and a range of individual health outcomes.

\section{Implications}

This study highlights the importance of residential stability for family well-being and child development and redounds to the social benefit of considering that we cannot have a healthy society when half a million families or more are homeless or struggling to attain residential stability. Highly mobile families in poverty were vulnerable to numerous internalizing and externalizing behavior problems and in higher need of mental health screening and services, increasing their risk of being homeless. Notably, families experiencing homelessness have many common characteristics to families in poverty, except the latter have independent housing (Annor \& Oudshoorn, 2019). Without responsive structural support, it will be difficult for the existing homeless families with children to escape 
homelessness and easy for vulnerable families in poverty to enter homelessness. Evidence shows that the availability of affordable housing significantly decreases a family's duration of homelessness (Cobb-Clark et al., 2014). Contrastingly, a lack of supportive policies and resources on housing and other determinants of health (e.g., education, employment, health care) may exacerbate adverse situations among disadvantaged families. As such, we suggest that policymakers secure the availability of affordable housing by rethinking current tenant-landlord laws in the face of rising public concerns about evictions and provide diverse housing options, such as housing subsidies or supportive housing, based on assessments of family needs. Policymakers should also consider reducing structural deficits related to housing issues, including but not limited to high unemployment rates, income inequality, discrimination, and disparities in health care. In terms of the long-term negative impacts of early-life residential instability on future health outcomes of individuals and families, strengthening housing-first policies and services that aim at helping people move from emergency/transitional housing status to stable housing as fast as possible is necessary. Housing first principles have proven effective in promoting housing retention and reducing homelessness (Collins et al., 2016; Ly \& Latimer, 2015).

Additionally, our findings recommend the use of interventions to address adolescent internalizing and externalizing problems that include a focus on caregiver social support and depression, especially when caregivers and their children have greater residential mobility. The effectiveness of intervention efforts designed to prevent adolescent behavioral health problems may be improved by providing social support for caregivers. Mental health practitioners, school social workers, and psychiatrists must continue to observe and record instances of adolescent mental health and behavior problems and their caregiver's mental health, such as depression. This monitor is especially important for adolescents and their caregivers who have experienced greater residential mobility and lack of social support. After screening the families living in disadvantaged housing status, social service providers may consider prevention and intervention programs to capitalize on support within these families' existing social networks and teach them general psychosocial skills (e.g., cognitive behavioral therapy) in ameliorating environmental stress. Furthermore, policymakers, school staff, and service providers working with families should consider high residential mobility as an important risk factor for children and adolescents and should consider social support for caregivers to address the internalizing and externalizing problems among their children. Given the bidirectional nature of social support - meeting individual's emotional and instrumental social support needs and influencing their perceived responsibility to offer support to others, support groups may be particularly useful because they can be sources of available community, information, and acceptance for people similar experiences. Belonging to these groups may provide an element of support that augmented other-network support; meanwhile, in support groups, people have opportunities to offer support to others, reassure their worth, and attain reliable alliances, thus improving their mental health.

\section{Conclusion}

By applying social determinants of health and a life-course perspective, our longitudinal analysis revealed that frequent residential mobility as a risk factor has a negative long-term impact on caregivers' mental health and their children's internalizing and externalizing problems. In contrast, caregiver social support as a protective factor reduces the negative impact on overall individual health outcomes. Highly mobile children and their caregivers were found to be vulnerable to numerous negative health outcomes and in high need of mental and behavioral health support and services. These findings inform important policy and practice implications on social support for mobile caregivers to address their children's mental and behavioral problems.

\section{Data Availability}

The dataset used in this study was provided by National Data Archive on Child Abuse and Neglect.

Acknowledgements We thank Dr. Timothy F. Page for revising our manuscript and providing wise comments.

Author contributions Xi Du: conceptualization, methodology, formal analysis, and writing manuscript. Youn Kyoung Kim: conceptualization, methodology, review and editing.

\section{Compliance with ethical standards}

Conflict of interest The authors declare no competing interests.

Ethics approval Ethical approval for this study was waived by the Institutional Review Board of Louisiana State University because we were doing secondary data analysis of the publicly available dataset.

Consent for publication We confirm that we have given the opportunity to be published by the Journal of Child and Family Studies.

Consent to participate Informed consent was not sought for the present study because information is publicly available and recorded information cannot readily be identified.

Publisher's note Springer Nature remains neutral with regard to jurisdictional claims in published maps and institutional affiliations. 


\section{References}

Abdul Rahman, M., Fidel Turner, J., \& Elbedour, S. (2015). The U.S. homeless student population: Homeless youth education. Review of research classifications and typologies, and the U.S. federal legislative response. Child \& Youth Care Forum, 44(5), 687-709. https://doi.org/10.1007/s10566-014-9298-2.

Achenbach, T. M. (1991). Manual for the child behavior checklist/418 and 1991 profile. University of Vermont, Department of Psychiatry.

Achenbach, T. M., \& Ruffle, T. M. (2000). The child behavior checklist and related forms for assessing behavioral/emotional problems and competencies. Pediatrics in review, 21(8), 265-271. https://doi.org/10.1542/pir.21-8-265.

Adam, E. K., \& Chase-Lansdale, P. L. (2002). Home sweet home(s): Parental separations, residential moves, and adjustment problems in low-income adolescent girls. Developmental Psychology, 38 (5), 792-805. https://doi.org/10.1037/0012-1649.38.5.792.

Anderson, S., Leventhal, T., \& Dupéré, V. (2014). Residential mobility and the family context: A developmental approach. Journal of Applied Developmental Psychology, 35(2), 70-78. https://doi. org/10.1016/j.appdev.2013.11.004.

Angley, M., Divney, A., Magriples, U., \& Kershaw, T. (2015). Social support, family functioning and parenting competence in adolescent parents. Maternal \& Child Health Journal, 19(1), 67-73. https://doi.org/10.1007/s10995-014-1496-x.

Annor, B. O. H., \& Oudshoorn, A. (2019). The health challenges of families experiencing homelessness. Housing, Care \& Support, 22(2), 93-105. https://doi.org/10.1108/HCS-12-2018-0036.

Beavers, W. R. \& Hampson, R. B. (1990). Successful families: Assessment and intervention. New York: W. W. Norton.

Benito-Gomez, M., Fletcher, A. C., \& Buehler, C. (2019). Youth parasympathetic functioning moderates relations between cumulative family risk and internalizing behaviors. Journal of Youth \& Adolescence, 48(11), 2307-2322. https://doi.org/10.1007/ s10964-019-01145-5.

Blackman, T., Anderson, J., \& Pye, P. (2003). Change in adult health following medical priority rehousing: A longitudinal study. Journal of Public Health Medicine, 25(1), 22-28. https://doi.org/ 10.1093/pubmed/fdg006.

Bradshaw, C. P., Mitchell, M. M. \& Leaf, P. J. (2010). Examining the effects of schoolwide positive behavioral interventions and supports on student outcomes: Results from a randomized controlled effectiveness trial in elementary schools. Journal of Positive Behavior Interventions, 12(3), 133-148. https://doi.org/10.1177/ 1098300709334798.

Braveman, P., \& Gottlieb, L. (2014). The social determinants of health: It's time to consider the causes of the causes. Public Health Reports, 129(Suppl 2), 19-31. https://doi.org/10.1177/ 00333549141291 S206.

Brown, M. A. (2015). Caregiver depression and social support in families with children with autism. APA PsycInfo.

Browne, M. W., \& Cudeck, R. (1992). Alternative ways of assessing model fit. Sociological Methods \& Research, 21(2), 230-258. https://doi.org/10.1177/0049124192021002005.

Casale, M., Cluver, L., Crankshaw, T., Kuo, C., Lachman, J. M., \& Wild, L. G. (2015). Direct and indirect effects of caregiver social support on adolescent psychological outcomes in two South African AIDS-affected communities. American Journal of Community Psychology, 55(3/4), 336-346. https://doi.org/10.1007/ s10464-015-9705-3.

Catalano, R. F. \& Hawkins, J. D. (1996). The social development model: A theory of antisocial behavior. In Hawkins, J. D. (Ed.), Delinquency and crime: Current theories. (pp. 149-197). Cambridge University Press.
Chiu, C. Y., Motl, R. W., \& Ditchman, N. (2016). Validation of the social provisions scale in people with multiple sclerosis. Rehabilitation Psychology, 61(3), 297-307. https://doi.org/10.1037/ rep0000089.

Chung-Yi, C., Motl, R. W., \& Ditchman, N. (2016). Validation of the social provisions scale in people with multiple sclerosis. Rehabilitation Psychology, 61(3), 297-307. https://doi.org/10.1037/ rep0000089.

Clark, W. A. V. (2013). Life course events and residential change: Unpacking age effects on the probability of moving. Journal of Population Research, 30(4), 319-334. https://doi.org/10.1007/ s12546-013-9116-y.

Cutrona, C. E., Cole, V., Colangelo, N., Assouline, S. G., \& Russell, D. W. (1994). Perceived parental social support and academic achievement: An attachment theory perspective. Journal of Personality and Social Psychology, 66(2), 369-378. https://doi.org/ 10.1037/0022-3514.66.2.369.

Cutrona, C. E. \& Russell, D. (1987). The provisions of social relationships and adaptation to stress. In Jones, W. H. \& Perlman, D. (Eds), Advances in personal relationships (Vol. 1, pp. 37-67). JAI Press.

Cobb-Clark, D. A., Herault, N., Scutella, R. \& Tseng, Y. (2014). A journey home: What drives how long people are homeless? Institute for the Study of Labor (IZA), No. 8495. https://ssrn. com/abstract $=2505357$.

Collins, C. C., D’Andrea, R., Dean, K. \& Crampton, D. (2016). Service providers' perspectives on permanent supportive housing for families. Families in Society: Journal of Contemporary Social Services, 97(3), 243-252. https://doi.org/10.1606/1044-3894. 2016.97.27.

Davis, M., LaShun, Y., Davis, S. P., \& Moll, G. (2008). Parental depression, family functioning, and obesity among African American children. Journal of cultural diversity, 15(2), 61-65.

Dempsey, J., McQuillin, S., Butler, A., \& Axelrad, M. (2016). Maternal depression and parent management training outcomes. Journal of Clinical Psychology in Medical Settings, 23(3), 240-246. https://doi.org/10.1007/s10880-016-9461-z.

Du, X. \& Kim, Y. K. (2020). Family functioning and adolescent behavior problems: A moderated mediation model of caregiver depression and neighborhood collective efficacy. Children and Youth Services Review, 116. https://doi.org/10.1016/j.childyouth. 2020.105270.

Edwards, M. C., Cheavens, J. S., Heiy, J. E., \& Cukrowicz, K. C. (2010). A reexamination of the factor structure of the center for epidemiologic studies depression scale: Is a one-factor model plausible? Psychological Assessment, 22(3), 711-715. https://doi. org/10.1037/a0019917.

Elder, G. (1998). The life course as developmental theory. Child Development, 69(1), 1-12. https://doi.org/10.2307/1132065.

Fisher, B. W., Mayberry, L., Shinn, M. \& Khadduri, J. (2014). Leaving homelessness behind: Housing decisions among familiesexiting shelter 1. Housing Policy Debate, 24(2), 364-386. https://doi.org/10.1080/10511482.2013.852603.

Foster, C. E., Webster, M. C., Weissman, M. M., Pilowsky, D. J., Wickramaratne, P. J., Rush, A. J., Hughes, C. W., Garber, J., Malloy, E., Cerda, G., Kornstein, S. G., Alpert, J. E., Wisniewski, S. R., Trivedi, M. H., Fava, M., \& King, C. A. (2008). Course and severity of maternal depression: Associations with family functioning and child adjustment. Journal of Youth \& Adolescence, 37(8), 906-916. https://doi.org/10.1007/s10964007-9216-0.

Fowler, P. J., Henry, D. B., \& Marcal, K. E. (2015). Family and housing instability: Longitudinal impact on adolescent emotional and behavioral well-being. Social Science Research, 53, 364-374. https://doi.org/10.1016/j.ssresearch.2015.06.012. 
García-Torres, F., Jacek Jabłoński, M., Gómez Solís, Á., Moriana, J. A., Jaén-Moreno, M. J., Moreno-Díaz, M. J., \& Aranda, E. (2020). Social support as predictor of anxiety and depression in cancer caregivers six months after cancer diagnosis: A longitudinal study. Journal of Clinical Nursing, 29(5/6), 996-1002. https://doi.org/10.1111/jocn.15123.

Goering, P., Tolomiczenko, G., Sheldon, T., Boydell, K., \& Wasylenki, D. (2002). Characteristics of persons who are homeless for the first time. Psychiatric Services, 53(11), 1472-1474. https:// doi.org/10.1176/appi.ps.53.11.1472.

Gould, T. E., \& Williams, A. R. (2010). Family homelessness: An investigation of structural effects. Journal of Human Behavior in the Social Environment, 20(2), 170-192. https://doi.org/10.1080/ 10911350903269765

Howland, A., Chen, L.-T., Chen, M.-E., \& Min, M. (2017). Exploring socio-demographics, mobility, and living arrangement as risk factors for academic performance among children experiencing homelessness. Preventing School Failure, 61(4), 268-279. https://doi.org/10.1080/1045988X.2016.1272541.

Hu, L. T., \& Bentler, P. M. (1999). Cutoff criteria for fit indexes in covariance structure analysis: Conventional criteria versus new alternatives. Structural Equation Modeling: A Multidisciplinary Journal, 6(1), 1-55. https://doi.org/10.1080/10705519909540118.

Department of Housing and Urban Development (2020). The 2019 Annual Homeless Assessment Report (AHAR) to Congress, Part 1: Point-in-time estimates of homelessness (p. 104). https://files. hudexchange.info/resources/documents/2019-AHAR-Part-1.pdf.

Hutchison, E. D. (2019). Dimensions of human behavior: The changing life course (6th ed.). Sage.

Jelleyman, T., \& Spencer, N. (2008). Residential mobility in childhood and health outcomes: A systematic review. Journal of Epidemiology \& Community Health, 62(7), 584-592. https://www. ncbi.nlm.nih.gov/pubmed/18559440.

Jones, N. L., Gilman, S. E., Cheng, T. L., Drury, S. S., Hill, C. V., \& Geronimus, A. T. (2019). Life course approaches to the causes of health disparities. American Journal of Public Health, 109, S48-S55. https://doi.org/10.2105/AJPH.2018.304738.

Kang, S. (2019). Why low-income households become unstably housed: Evidence from the panel study of income dynamics. Housing Policy Debate, 29(4), 559-587. https://doi.org/10.1080/ 10511482.2018.1544161.

Kingston, S. (2013). Economic adversity and depressive symptoms in mothers: Do marital status and perceived social support matter? American Journal of Community Psychology, 52(3/4), 359-366. https://doi.org/10.1007/s10464-013-9601-7.

Konowałek, Ł., \& Wolanczyk, T. (2018). Changes in emotional and behavioral problems between 2000 and 2011 among 16-year-old polish children: A cross-sectional study. Child Psychiatry \& Human Development, 49(5), 757-765. https://doi.org/10.1007/ s10578-018-0791-y.

Ly, A., \& Latimer, E. (2015). Housing first impact on costs and associated cost offsets: A review of the literature. Canadian journal of psychiatry. Revue canadienne de psychiatrie, 60(11), 475-487. https://doi.org/10.1177/070674371506001103.

MacKinnon, D. P., Fairchild, A. J. \& Fritz, M. S. (2007). Mediation analysis. Annual review of psychology, 58, 593-614. https://doi. org/10.1146/annurev.psych.58.110405.085542.

Magdol, L. (2002). Is moving gendered? The effects of residential mobility on the psychological well-being of men and women. Sex Roles: A Journal of Research, 47(11-12), 553-560. https://doi. org/10.1023/A:1022025905755.

Maimon, D., \& Browning, C. R. (2010). Unstructured socializing, collective efficacy, and violent behavior among urban youth. Criminology, 48(2), 443-474. https://doi.org/10.1111/j.17459125.2010.00192.x
Marshall, N. L., Noonan, A. E., McCartney, K., Marx, F., \& Keefe, N. (2001). It takes an urban village parenting networks of urban families. Journal of Family Issues, 22(2), 163-182. https://doi. org/10.1177/019251301022002003.

Miller-Graff, L., Howell, K., Martinez-Torteya, C., Grein, K., MillerGraff, L. E., \& Howell, K. H. (2017). Direct and indirect effects of maltreatment and social support on children's social competence across reporters. Child Psychiatry \& Human Development, 48(5), 741-753. https://doi.org/10.1007/s10578-016-0698-4.

Mok, P. L. H., Webb, R. T., Appleby, L., \& Pedersen, C. B. (2016). Full spectrum of mental disorders linked with childhood residential mobility. Journal of Psychiatric Research, 78, 57-64. https://doi.org/10.1016/j.jpsychires.2016.03.011.

Moran, L., Garrity, S., McGregor, C., \& Devaney, C. (2019). Hoping for a better tomorrow: a qualitative study of stressors, informal social support and parental coping in a Direct Provision centre in the West of Ireland. Journal of Family Studies, 25(4), 427-442. https://doi.org/10.1080/13229400.2017.1279562.

Morris, T., Manley, D., \& Sabel, C. E. (2018). Residential mobility. Progress in Human Geography, 42(1), 112-133. https://doi.org/ 10.1177/0309132516649454.

Morris, T. T., Northstone, K., \& Howe, L. D. (2016). Examining the association between early life social adversity and BMI changes in childhood: A life course trajectory analysis. Pediatric Obesity, 11(4), 306-312. https://doi.org/10.1111/ijpo.12063.

National Alliance to End Homelessness (2020, January). Children and families. https://endhomelessness.org/homelessness-in-america/w ho-experiences-homelessness/children-and-families/

National League of Cities. (2020). The eviction prevention cohort: Highlights from the five-city pilot. https://www.nlc.org/wpcontent/uploads/2021/01/TheEvictionPreventionCohortReport_ 2020.pdf

Prince, D. M., Hohl, B., Hunter, B. A., Thompson, A. B., Matlin, S. L., Hausman, A. J., \& Tebes, J. K. (2019). Collective efficacy as a key context in neighborhood support for urban youth. American Journal of Community Psychology, 63(1/2), 179-189. https://doi. org/10.1002/ajcp.12311.

R Core Team (2019). R: A language and environment for statistical computing. In $\mathrm{R}$ Foundation for Statistical Computing. https://www.R-project.org/.

Radloff, L. S. (1977). The CES-D Scale: A self-report depression scale for research in the general population. Applied Psychological Measurement, 1(3), 385-401. https://doi.org/10.1177/014662167700100306.

Rog, D. J., Henderson, K. A., \& Greer, A. L. (2015). Family stability and child welfare involvement among families served in permanent supportive housing. Child Welfare, 94(1), 189-208.

Rosseel, Y. (2012). lavaan: An R package for structural equation modeling. Journal of Statistical Software, 48(2), 1-36. https:// doi.org/10.18637/jss.v048.i02.

Roze, M., Vandentorren, S., van der waerden, J., \& Melchior, M. (2018). Factors associated with depression among homeless mothers results of the ENFAMS survey. Journal of Affective Disorders, 229, 314-321. https://doi.org/10.1016/j.jad.2017.12. 053.

Runyan, D., Dubowitz, H., English, D. J., Kotch, J. B., Litrownik, A., Thompson, R. \& Group, T. L. I. (2014). Longitudinal studies of child abuse and neglect (LONGSCAN) Assessments 0-18 [Data set]. National Data Archive on Child Abuse and Neglect. http://www.ndacan.cornell.edu.

Runyan, D. K., Curtis, P. A., Hunter, W. M., Black, M. M., Kotch, J. B., Bangdiwala, S., Dubowitz, H., English, D., Everson, M. D., \& Landsverk, J. (1998). LONGSCAN: A consortium for longitudinal studies of maltreatment and the life course of children. Aggression and Violent Behavior, 3(3), 275-285. https://doi.org/ 10.1016/S1359-1789(96)00027-4. 
Sheidow, A., Henry, D., Tolan, P., \& Strachan, M. (2014). The role of stress exposure and family functioning in internalizing outcomes of urban families. Journal of Child \& Family Studies, 23(8), 1351-1365. https://doi.org/10.1007/s10826-013-9793-3.

Stabler, M., Gurka, K., \& Lander, L. (2015). Association between childhood residential mobility and non-medical use of prescription drugs among american youth. Maternal \& Child Health Journal, 19(12), 2646-2653. https://doi.org/10.1007/s10995-015$1785-\mathrm{z}$.

Stansbury, J. P., Ried, L. D., \& Velozo, C. A. (2006). Unidimensionality and bandwidth in the center for epidemiologic Studies depression (CES-D) scale. Journal of Personality Assessment, 86(1), 10-22. https://doi.org/10.1207/s15327752jpa 8601_03.

Susukida, R., Mojtabai, R., Murcia, G., \& Mendelson, T. (2016). Residential mobility and risk of major depressive episode among adolescents in the National survey on drug use and health. Journal of Public Health, 38(3), 432-440. https://doi.org/10. 1093/pubmed/fdv100.

Teo, P. L., \& Chiu, M. Y.-L. (2016). An ecological study of families in transitional housing - 'housed but not homed. Housing Studies, 31 (5), 560-577. https://doi.org/10.1080/02673037.2015.1106064.

Theodos, B., McTarnaghan, S. \& Coulton, C. (2018). Family residential instability: What can states and localities do? Urban Institute. https://www.urban.org/sites/default/files/publication/98286/family_ residential_instability_what_can_states_and_localities_do_1.pdf.

Tseliou, F., Maguire, A., Donnelly, M., \& O'Reilly, D. (2016). The impact of childhood residential mobility on mental health outcomes in adolescence and early adulthood: a record linkage study. Journal of Epidemiology \& Community Health, 70(3), 278-285. https://doi.org/10.1136/jech-2015-206123.
Tunstall, H., Cabieses, B., \& Shaw, R. (2012). The characteristics of mobile families with young children in England and the impact of their moves on neighbourhood inequalities in maternal and child health. Health \& Place, 18(3), 657-670. https://doi.org/10.1016/j. healthplace.2011.11.009.

U.S. Census Bureau (n.d.). Historical poverty tables: People and families - 1959 to 2019. https://www.census.gov/data/tables/timeseries/demo/income-poverty/historical-poverty-people.html.

Voight, A., Giraldo-García, R., \& Shinn, M. (2020). The effects of residential mobility on the education outcomes of urban middle school students and the moderating potential of civic engagement. Urban Education, 55(4), 570-591. https://doi.org/10.1177/ 0042085917721956.

Webb, R. T., Pedersen, C. B., \& Mok, P. L. H. (2016). Adverse outcomes to early middle age linked with childhood residential mobility. American Journal of Preventive Medicine, 51(3), 291-300. https://doi.org/10.1016/j.amepre.2016.04.011.

Weiss, R. S. (1974). The provisions of social relationships. In Rubin, Z. (Ed.), Doing unto others (pp. 17-26). Prentice Hall.

Winetrobe, H., Wenzel, S., Rhoades, H., Henwood, B., Rice, E., \& Harris, T. (2017). Differences in health and social support between homeless men and women entering permanent supportive housing. Women Health Issues, 27(3), 286-293. https://doi. org/10.1016/j.whi.2016.12.011.

World Health Organization. (n.d.). About social determinants of health. https://www.who.int/social_determinants/sdh_definition/en/.

Woodhead, C., Aschan, L., Lynskey, M. T., Polling, C., Goodwin, L., \& Hatch, S. L. (2015). Exploring evidence for a prospective relationship between common mental disorder and meeting residential mobility preferences. Health \& Place, 32, 19-28. https:// doi.org/10.1016/j.healthplace.2014.12.013. 